\title{
PERANCANGAN LEARNING MANAGEMENT SYSTEM SEBAGAI PENDUKUNG PEMBELAJARAN JARAK JAUH
}

\author{
Phie Chyan \\ Program Studi Teknik Informatika, Fakultas Teknologi Informasi, Universitas Atma Jaya Makassar \\ Jl. Tanjung Alang No 23 Makassar - Sulawesi Selatan - Indonesia \\ E-mail : phiechyan@gmail.com
}

\begin{abstract}
ABSTRAK
Sistem pendidikan jarak jauh (PJJ) merupakan suatu inovasi teknologi dalam dunia pendidikan. PJJ merupakan sistem pendidikan yang memiliki daya jangkau luas lintas ruang, waktu, dan sosioekonomi serta memungkinkan akses pendidikan bagi siapa saja, di mana saja, dan kapan saja. Pada tahun 2018, angka partisipasi kasar pendidikan tinggi di Indonesia mencapai 33,3\%. belum mendekati target nasional di 50\% pada tahun 2024. Penelitian ini berfokus untuk merancang Learning Management System (LMS) untuk mendukung penerapan pembelajaran jarak jauh dan mampu mendukung penyusunan, penggandaan dan distribusi bahan ajar, proses penilaian belajar dalam berbagai bentuk model evaluasi belajar dan mendukung interaksi antara pengajar dan siswa melalui berbagai bentuk interaksi menggunakan media audio visual. Untuk mencapai tujuan penelitian maka penelitian dilaksanakan dalam beberapa tahap mengikuti model perancangan waterfall. Hasil yang diperoleh adalah sebuah LMS yang mampu memenuhi kebutuhan belajar mengajar secara jarak jauh maupun blended learning yang telah diimplementasikan dalam lingkungan universitas Atma Jaya Makassar.
\end{abstract}

Kata Kunci: Pembelajaran, LMS, Media

\section{ABSTRACT}

The distance education system (PJJ), which is technology inovation in education system that has broad outreach across space, time and socioeconomics. The PJJ system opens access to education for anyone, anywhere and at any time. In 2018, the gross enrollment rate of higher education in Indonesia will reach 33.3\%. still far from achieving the national target, which is $50 \%$ by 2024. This research focuses on designing a Learning Management System (LMS) to support the application of distance learning which will be able to support the preparation, presupposition and distribution of teaching materials, the process of learning assessment in various forms of learning evaluation models and to support interactions between instructors and students through various forms of interaction using audio visual media. To achieve the research objectives, the research was carried out in several stages following the waterfall design model. The results obtained are an LMS that is able to meet the needs of teaching and learning in distance and blended learning and have been implemented in Atma Jaya University of Makassar.

Keyword: Learning, LMS, Media

\section{PENDAHULUAN}

Sistem pendidikan jarak jauh (PJJ) merupakan suatu inovasi teknologi dalam dunia pendidikan. PJJ merupakan sistem pendidikan yang memiliki daya jangkau luas lintas ruang, waktu, dan sosioekonomi serta memungkinkan akses pendidikan bagi siapa saja, di mana saja, dan kapan saja. Dengan didukung payung hukum yang telah diterbitkan pemerintah yaitu SK Mendiknas No. 107/U/2001, UU Sisdiknas No. 20/2003, PP 17/2010, dan juga PP 66/2010, sistem PJJ sudah menjadi salah satu metode pendidikan yang diterima oleh sistem pendidikan di Indonesia [1]. Hal ini mendorong berbagai institusi pendidikan untuk terlibat dalam mengembangkan sistem pendidikan jarak jauh ini. Pandemi Covid 19 yang melanda seluruh dunia yang menyebabkan sebagian besar sekolah hingga perguruan tinggi harus menyesuaikan metode pembelajaran dari model tatap muka konvensional ke bentuk pembelajaran digital turut meningkatkan popularitas dan kesadaran para pelaku pendidikan akan pentingnya pemanfaatan teknologi dalam mendukung dunia pendidikan yang pada prinsipnya merupakan teknologi yang disiapkan untuk juga mendukung 
pembelajaran jarak jauh.

Pada tahun 2018, angka partisipasi kasar pendidikan tinggi di Indonesia ada di angka $33,3 \%$. Ini merupakan suatu peningkatan yang signifikan dari tahun-tahun sebelumnya, tetapi masih butuh kerja keras untuk dapat menjangkau target nasional di angka $50 \%$ di tahun 2024 [2]. Dalam PP 17/2010 pasal 118 menyatakan bahwa PJJ diselenggarakan dengan tujuan meningkatkan perluasan dan pemerataan akses pendidikan, serta meningkatkan mutu dan relevansi pendidikan. Karena itu PJJ digambarkan memiliki beberapa karakteristik positif antara lain terbuka, belajar mandiri, belajar tuntas, memanfaatkan teknologi informasi dan komunikasi (TIK), dan/atau menggunakan teknologi lainnya. Melalui sistem PJJ, setiap orang dapat memiliki akses ke pendidikan secara lebih fleksibel tanpa perlu mengorbankan banyak hal seperti kesempatan karir, pekerjaan hingga keluarga. Sifat terbuka dan masif dari sistem PJJ dalam mendistribusikan pendidikan berkualitas yang terstandar dengan memanfaatkan TIK, standardisasi capaian pembelajaran (learning outcomes), materi ajar, proses pembelajaran, bantuan belajar, dan evaluasi pembelajaran, menjadikan pendidikan berkualitas dapat diperoleh oleh semua kalangan tanpa harus dibatasi dengan hambatan-hambatan yang umum ditemui pada sistem pendidikan konvensional.

Secara umum definisi dari PJJ adalah Pendidikan yang peserta didiknya terpisah dari pendidik dan kegiatan pembelajarannya dilaksanakan dengan menggunakan berbagai sumber belajar melalui teknologi informasi, komunikasi dan media lain [3]. Universitas Atma Jaya Makassar (UAJM) sebagai salah satu institusi penyelenggara pendidikan tinggi diharapkan juga dapat ikut serta dalam program ini untuk mewujudkan cita-cita sebagai institusi pendidikan tinggi yang terkemuka di Indonesia
Timur terlebih lagi UAJM merupakan salah satu perguruan tinggi yang berafiliasi dalam Asosiasi Perguruan Tinggi Katholik Indonesia (APTIK) yang juga telah menerapkan sistem PJJ diantara perguruan tinggi anggotanya untuk saling bertukar program atau kelas yang menjadi unggulan dari satu perguruan tinggi dengan perguruan tinggi lain.

Dalam melaksanakan PJJ dibutuhkan perancangan kurikulum, ragam proses pembelajaran hingga materi ajar yang sesuai dan kesemuanya membutuhkan pemanfaatan TIK dalam mendukung berbagai aktifitas pembelajaran termasuk didalamnya administrasi pembelajaran seperti registrasi atau enrollment, penyusunan rencana pembelajaran semester, penyusunan dan distribusi bahan ajar, berbagai bentuk pembelajaran seperti kegiatan praktikum, tutorial, responsi dan ujian serta layanan lain seperti forum diskusi hingga live chat [4].

Penelitian ini berfokus untuk merancang Learning Management System (LMS) untuk mendukung penerapan pembelajaran jarak jauh. LMS yang dikembangkan akan mampu mendukung penyusunan, pengandaan dan distribusi bahan ajar, proses penilaian belajar dalam berbagai bentuk model evaluasi belajar dan mendukung interaksi antara pengajar dan siswa melalui berbagai bentuk interaksi menggunakan media audio visual [5].

Penelitian dalam ranah penelitian media pembelajaran seperti LMS telah menjadi topik penelitian yang aktif diteliti diantaranya adalah Ujulawa $M$ dalam penelitiannya perancangan Learning Management System (LMS) menggunakan Moodle pada Sekolah Tinggi Tarakanita Jakarta [6] yang menggunakan perangkat lunak Moodle sebagai basis perancangan untuk mengembangkan LMS bagi Sekolah tinggi Tarakanita. Selain itu penelitian dari Komendangi et al yang menganalisis dan mengembangkan LMS prodi teknik pertanian 
Universitas Sam Ratulangi juga dengan memanfaatkan Moodle [7]. Perangkat lunak bantu seperti Moodle cukup membantu dalam mengembangkan LMS akan tetapi kekurangannya sulit untuk melakukan kostumisasi sesuai dengan kebutuhan institusi. Berdasarkan latar belakang penelitian yang telah dirumuskan maka tujuan dari penelitian ini adalah merancang dan mengimplementasikan model learning management system (LMS) yang khusus dikembangkan untuk mendukung pembelajaran jarak jauh yang sesuai dengan kebutuhan institusi. Luaran penelitian yang ditargetkan adalah menghasilkan model learning management system untuk mendukung pembelajaran jarak jauh.

\section{METODE}

Untuk mencapai tujuan penelitian maka kegiatan penelitian dibagi dalam beberapa tahap mengikuti model perancangan Waterfall yang umum digunakan dalam pengembangan perangkat lunak dan menitikberatkan pada urutan pengembangan secara berurutan dan sistematis. Dalam penelitian ini tahap - tahap pengembangan sistem dibagai dalam beberapa tahap dengan urutan sebagai berikut, 1) Studi literatur, 2) Pengumpulan data, 3) Perancangan Sistem, 4) Implementasi sistem aplikasi, 5) Analisis sistem dan evaluasi, dan 6) Penyampaian laporan penelitian dan publikasi. Lokasi penelitian akan dilaksanakan pada Laboratorium Komputer Pemrograman dan Simulasi Fakultas Teknologi Informasi Universitas Atma Jaya Makassar.

\section{Studi Literatur}

Studi literatur dilakukan untuk mendapatkan dasar teoritis dan juga metode analisis terkini agar diperoleh hasil yang sesuai dengan perkembangan dalam bidang ilmu teknologi informasi dan multimedia. Kegiatan yang dilakukan pada tahapan ini adalah mengumpulkan dan mempelajari artikel, jurnal dan referensi lain nya yang mutakhir berkaitan dengan Leearning Management System (LMS) dan pembelajaran jarak jauh.

\section{Pengumpulan Data}

Mengumpulkan data yang berkenaan dengan data pendukung dalam proses implementasi aplikasi Learning Management System yang akan dijalankan. Data yang dikumpulkan mencakup data silabus, rencana pembelajaran dan materi ajar yang dikumpulkan dari dosen pengajar matakuliah berupa diktat, handout, dan slide presentasi.

Pengumpulan data penelitian dilakukan dengan melakukan wawancara kepada dosen pengampu matakuliah di universitas Atma Jaya Makassar (UAJM) untuk mendapatkan masukan mengenai model pembelajaran yang digunakan dalam lingkungan universitas dan bagaimana penggunaan teknologi melalui layanan LMS dapat memberikan fasilitas yang dibutuhkan oleh dosen. Pengumpulan data melalui kuisioner juga dilakukan kepada mahasiswa peserta matakuliah untuk dapat mengetahui pengalaman mahasiswa dalam menggunakan pembelajaran melalui daring dan apa hambatan yang diperoleh selama mengikut moda pembelajaran tersebut.

\section{Perancangan Sistem}

Pada tahap ini dilakukan perancangan Learning Management System yang dapat digunakan untuk menfasilitasi pembelajaran jarak jauh. Modul - modul dari LMS mencakup modul registrasi. Fasilitas pembuatan bahan ajar berbasis multimedia, forum diskusi, modul assesment yang digunakan untuk menilai kemajuan proses belajar, modul interaksi pengajar dan siswa dengan berbagai media audio visual [8], [9].

\section{Implementasi Sistem Aplikasi}

Pada tahap ini dilakukan implementasi secara keseluruhan dari desain sistem aplikasi yang dikembangkan. Pada proses implementasi sistem perhatian ditujukan terhadap bagaimana membuat materi ajar yang sesuai dengan model 
pembelajaran jarak jauh.

\section{Analisa Sistem dan Evaluasi}

Setelah dilakukan implementasi, pada tahap analisa sistem ini terdapat beberapa hal yang dapat dianalisa berdasarkan hasil dari sistem yaitu apakah seluruh fitur yang disediakan dapat dimengerti dan dimanfaatkan dengan baik oleh dosen dan mahasiswa, bagaimana menerapkan materi ajar yang sesuai dan bagaimana performa sistem dalam mendukung interaksi pengajar dan siswa dalam modus audio visual melalui jaringan komputer. Dalam tahapan ini juga akan dievaluasi umpan balik dari pengguna sistem mengenai kesulitan kesulitan yang dihadapi selama menggunakan LMS serta fitur-fitur yang mereka harapkan ada tapi belum dapat diakomodasi oleh sistem yang dikembangkan.

\section{HASIL}

\section{Analisa Kebutuhan}

Berdasarkan hasil pengumpulan data yang dilakukan kepada dosen pemgampu matakuliah ada beberapa fitur layanan pada LMS yang sangat penting untuk dapat disediakan oleh layanan LMS antara lain: Fitur enrollment Matakuliah bagi mahasiswa, layanan penyampaian pengumuman, Model latihan soal yang beragam, fitur penugasan mata kuliah dan model interaksi [10]. Model interaksi yang diinginkan selain berbasis teks juga mampu mendukung model audio visual. Berdasarkan hasil kuisioner dari mahasiswa disimpulkan bahwa rata-rata mahasiswa sebagai peserta matakuliah menginginkan interface LMS yang lengkap tapi mudah digunakan, dapat dijalankan pada spesifikasi komputer rata-rata, user friendly serta ramah bandwidth.

\section{Desain Sistem}

Sistem dikembangkan dengan basis claroline versi 3.2 menggunakan PHP dan mysql yang berjalan diatas web server Apache. Berikut gambar 1 menampilkan desain dari model ELearning yang dirancang.

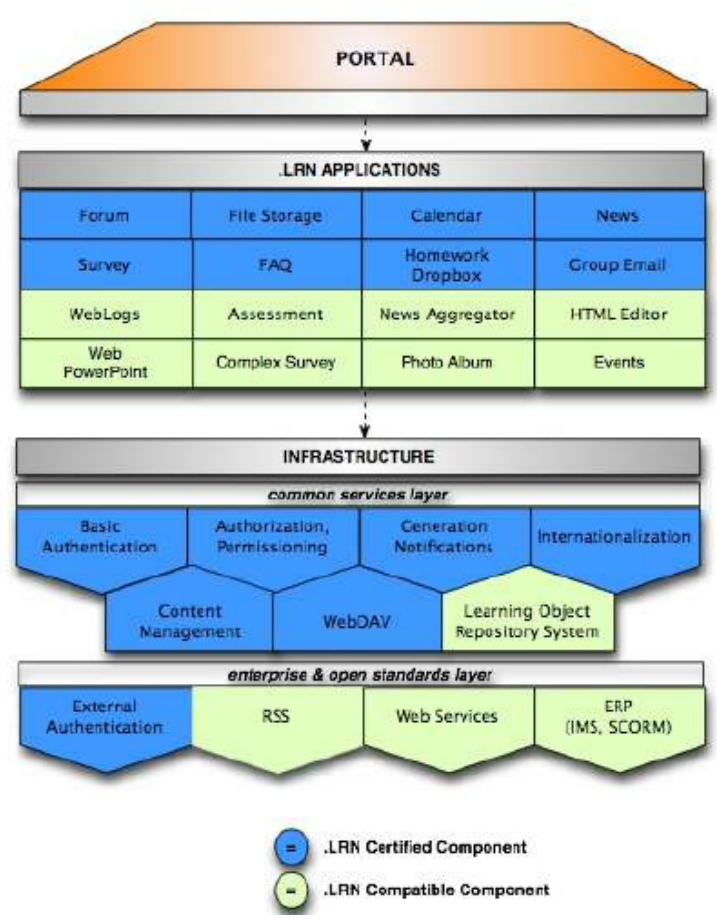

Gambar 1. UAJM LMS Model

Model LMS yang dirancang pada gambar 1.terdiri dari fitur-fitur dasar yang dibutuhkan dalam proses belajar mengajar sesuai dengan analisa kebutuhan yang dirancang. Beberapa fitur yang tersedia antara lain

a. Authentikasi - Komponen ini bertujuan untuk memberikan pengelolaan akun dosen dan mahasiswa dengan menyediakan berbagai fungsi sesuai dengan jenis pengguna (dosen atau mahasiswa) - bagi dosen tersedia layanan untuk pengelolaan mata kuliah, kelas dan unsur-unsurnya sedangkan bagi mahasiswa tersedia layanan untuk pendaftaran matakuliah, pengelolaan calendar dan lain-lain

b. Content management- komponen ini bertujuan untuk memberikan layanan pengelolaan storage, manajemen file, konten forum dan chat.

Learning object system - komponen ini 
berfungsi untuk menyediakan berbagai bentuk pembuatan latihan, penugasan, penilaian feedback dan alur pembelajaran

\section{Implementasi}

Berdasarkan hasil pengujian yang dilakukan terutama dalam mendukung pembelajaran daring dimasa pandemi covid-19. LMS yang dikembangkan mampu mengakomodasi kebutuhan proses belajar mengajar yang biasanya dilakukan secara konvensional. Sebagian besar dosen dapat menggunakan LMS dengan baik begitupun dengan mahasiswa walaupun tanpa dilakukan pelatihan sebelumnya, hal ini terjadi karena dalam mendesain model LMS memang dibuat agar sedapat mungkin user-friendly dan mudah digunakan dengan metode menampilkan fungsi-fungsi sederhana pada layer atas dan menyembunyikan fitur-fitur yang advanced pada layer dibawah, hal ini memungkinkan LMS tampil sederhana dan intuitive tapi tetap menyediakan fitur-fitur yang lebih advanced apabila pengguna ingin mengeksplorasi lebih jauh. Berikut beberapa komponen LMS yang telah diimplemetasikan dalam LMS UAJM.

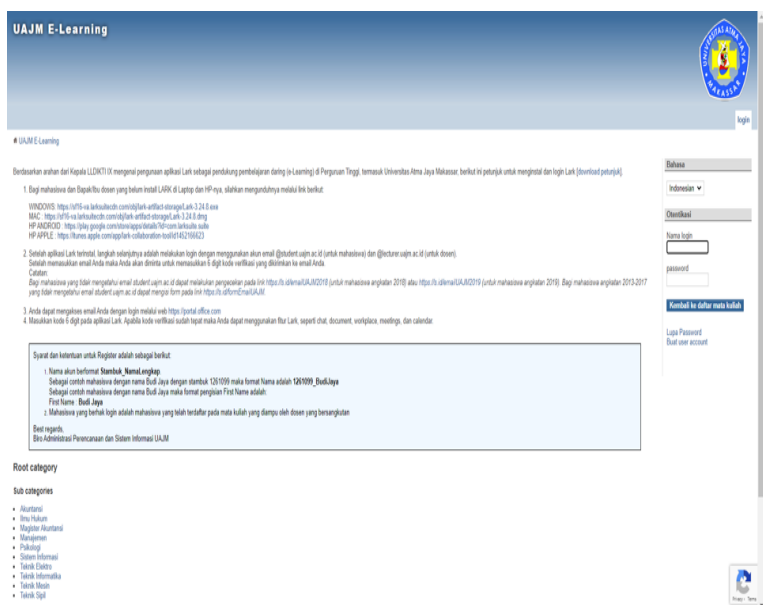

Gambar 2. Menu Utama LMS UAJM

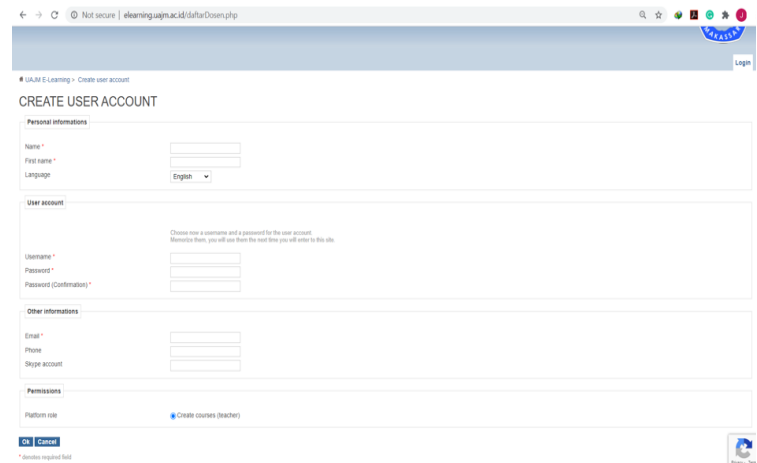

Gambar 3. Menu Daftar Dosen / Mahasiswa

Gambar 2 dan 3 menunjukkan menu utama yang dilihat oleh dosen dan mahasiswa ketika mengakses LMS, di menu utama tersedia menu login dan juga pendaftaran untuk dosen dan mahasiswa. Dosen dan mahasiswa yang mendaftar masuk ke dalam sistem akan divalidasi terlebih dahulu oleh admin universitas apabila valid baru akun tersebut diaktifkan dan bisa digunakan. Setelah pengguna dalam hal ini dosen dan mahasiswa berhasil login kedalam sistem maka selanjutnya pengguna dapat mengakses berbagai fitur dan fungsi melalui control panelnya sesuai dengan role pengguna tersebut apakah sebagai dosen atau mahasiswa. Bagi dosen fitur spesifik yang tersedia adalah melakukan manajamen matakuliah dan kelas sedangkan fitur spesifik bagi mahasiswa adalah melakukan proses enrollment terhadap matakuliah yang diikuti. Tampilan control panel bagi dosen dapat dilihat pada gambar 4 berikut:

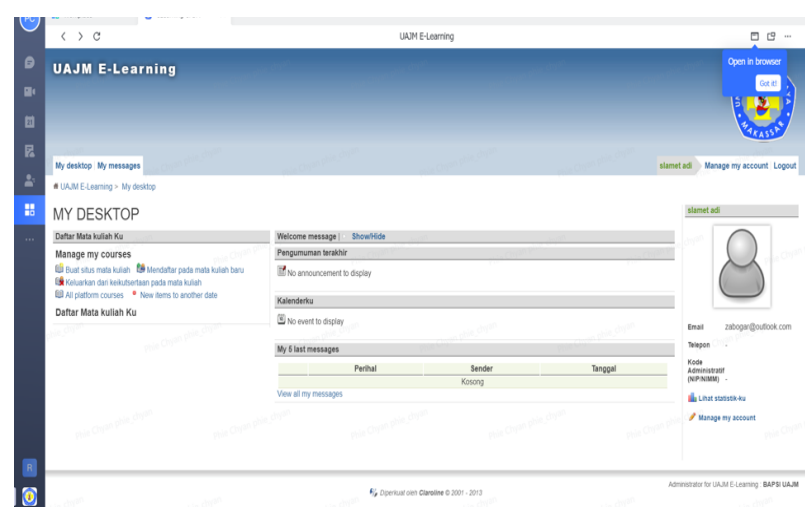

Gambar 4. Control Panel Dosen 
Fitur-fitur manajemen matakuliah yang dapat diakses melalui control panel seperti yang terlihat pada gambar 5 adalah pembuatan matakuliah,membuat pengumuman, mengelola dokumen kuliah, menampilkan Rencana Pembelajaran Semester (RPS) dan Capaian pembelajaran, membuat penugasan dalam berbagai jenis metode evaluasi dan sebagainya.

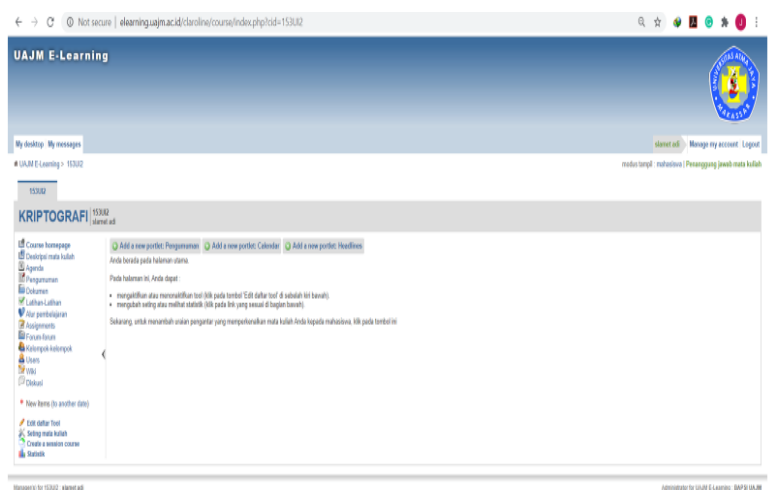

Gambar 5. Fitur Manajemen Matakuliah

Dilihat dari fungsi statistic yang tersedia dalam LMS, penggunaan LMS dalam mendukung pembelajaran telah mampu tercapai dilihat dari parsitipasi dosen dalam menggunakan media LMS internal UAJM mencapai 75 persen dari keseluruhan dosen, sisanya 25 persen masih mengandalkan aplikasi lain seperti google classroom, edmodo, zoom dll kedepannya diharapkan lebih banyak lagi dosen dapat menggunakan LMS internal kampus setelah diadakan sosialisasi yang lebih intensif. Dari sisi mahasiswa 90 persen mahasiswa puas dengan layanan yang tersedia melalui LMS UAJM, beberapa keunggulan yang dinyatakan oleh mahasiswa antara lain kemudahan penggunaaan, kemudahan yang diberikan oleh fitur penjadwalan dan pengumuman, hemat bandwidth terlebih lagi karena LMS UAJM telah terdaftar dalam ilmupedia yaitu program akses murah dari salah satu provider telekomunikasi di indonesia yang memungkinkan mahasiswa dapat mengakses LMS kampus dengan biaya kuota yang lebih murah

\section{KESIMPULAN}

LMS yang dirancang telah mendukung berbagai komponen yang dibutuhkan dalam mendukung pelaksanaan pendidikan jarak jauh dan blended learning termasuk kemampuan untuk diintegrasikan dengan sistem lain untuk memperluas kapabilitas sistem.

\section{DAFTAR PUSTAKA}

[1] A. Taufik, "Perspektif Tentang Perkembangan Sistem Pembelajaran Jarak Jauh Di Kabupaten Kutai Kartanegara Kalimantan Timur," J. Pendidikan\&Konseptual, vol. 3, no. 2, pp. 88-98, 2019.

[2] BPS, "Angka Partisipasi Kasar Pendidikan Tinggi," 2019.

[3] I. P. Ramayasa, "Evaluation Model of Success and Acceptance of E-Learning," J. Theor. Appl. Inf. Technol., vol. 3182, no. 3, pp. 462-469, 2015.

[4] R. . Utomo, "MOOCs as an alternative to distance learning model for University in Indonesia," in 2014 International Conference on ICT For Smart Society (ICISS), 2014, pp. 182-184.

[5] B. Saputro and A. T. Susilowati, "Effectiveness of Learning Management System (LMS) on In-Network Learning System (SPADA) based on scientific," $J$. Educ. Gift. Young Sci., vol. 7, no. 3, pp. 481-498, 2019.

[6] M. Ujulawa and Matilda, "Perancangan Learning Management System (LMS) Menggunakan Moodle Pada Sekolah Tinggi Tarakanita" Jurnal Ilmiah Komputasi, vol. 16, no. 1, 2017.

[7] F.K Komendangi, R. Molenaar and L. Lengkey, "Analisis dan Perancangan Aplikasi E-Learning Berbasis Learning Management System (LMS) Moodle Di Program Studi Teknik Pertanian Universitas Sam Ratulangi" COCOS, vol. 1, no. 3, 2017.

[8] P. Chyan and S. C. Sumarta, "Rancang 
bangun mesin pencari citra dengan pendekatan temu balik berbasis konten," TEMATIKA, vol. 3, no. 2, 2017.

[9] P. Chyan and S. C. Sumarta, "Sistem temu balik citra berbasis isi citra menggunakan fitur warna dan jarak histogram," TEMATIKA, vol. 2, no. 2, pp. 31-38, 2016.

[10] P. Chyan, "Perancangan sistem informasi perparkiran pada universitas atma jaya makassar," TEMATIKA, vol. 1, no. $1,2016$. 